\title{
Comments on IPCC's 7th August 2019 Report on "Climate Change and Land"
}

\section{S Jeevananda Reddy*}

Chief Technical Advisor - WMO/UN and Expert - FAO/UN, Fellow, Telangana Academy of Sciences, Convener Forum for a Sustainable Environment, Hyderabad, India

*Corresponding Author: S Jeevananda Reddy, Chief Technical Advisor - WMO/UN and Expert - FAO/UN, Fellow, Telangana Academy of Sciences, Convener Forum for a Sustainable Environment, Hyderabad, India

Received: August 13, 2019; Published: August 19, 2019

DOI: 10.31080/ASAG.2019.03.0624

Under "Summary for Policy makers", the report states that "This report addresses greenhouse (GHG) fluxes in land-based ecosystem, land use and sustainable land management in relation to climate change adaptation and mitigation, desertification, land degradation and food security". That is, tried to link all these to global warming/GHG. However, all these factors are localized and regionalized but not globalized. Mississippi River in USA receives heavy doses of chemical wastes from farm field runoffs and created Gulf of Mexico a dead zone, etc., etc. Destruction of nature to meet human greed, the "same extreme weather event's" impact is amplified" multi-fold. Decades back a WMO report brought out some such facts.

As usual, this is one another "Time-pass Report - Wasting Public Money" from IPCC a UN body. Most of the descriptions in the report are of hypothetical in nature derived from the Air with the pre-conceived notions and are not based on physics/Science. Unfortunately, they even did not take note of what they said in their earlier reports such as AR4 and AR5 in terms of definition of "climate change", climate system, climate sensitivity factor, etc.

The main fallacy in declaring an event as unusual is based on the past few years' records. The meteorological records started only around 1850s and that too at fewer locations. With the progression of time they increased in number covering wider space. Prior to 1850 only some documents-folklores narrated unusual weather events but they are rarely available to public to consult like data. The modern politicians-UN agencies-some scientific groups-NGO groups have been attributing the unusual weather events to global warming for the lapses committed by the government bodies- public; and the media gives them hype [1,2]. In all the unusual weather events they used invariably the word "climate change" but while discussing the events they talk of impact of "temperature", which refers indirectly to "global warming, a component of climate change. However, such people avoid using the word global warming.

"We cannot expect the Paris Agreement to solve the crisis associated with these extreme weather events. The way was to minimize their impact is through the mechanism in which they occur by quantifying the agro-climate of the region" - Ecologise.in, 6th June 2016; "Precautionary measure for natural calamities: A letter to the Prime Minister" - such analysis was carried out for few countries and the summaries were included in Reddy [3,4].

The traditional agriculture was soil and climate driven farming systems that encompasses the animal husbandry [5]. It provided socio-economic, food and nutrient security with the healthy food. Those were the "Golden Days" in the history of farming. Traditionally farmers adapted to this based on their forefathers hundreds of years of experiences. Now, quality milk and Aqua products have become rare commodities. To achieve food security, we need sustainable agriculture system under variable soil and climate conditions wherein the soil is static and the climate is dynamic $[3,4]$. Climate is beyond human control and thus needs to adapt to it. Climate is always changing through the natural cycles. What we are experiencing now is part of this system only. The two main climatic parameters that play vital role in agriculture are temperature and precipitation. Temperature presents high seasonal and annual variations. Table presents the Hyderabad Temperature Extremes from 
climate normal book. The range shows more than $10 \mathrm{oC}$. At all India level 2002 and 2009 were drought years. This resulted raise in temperature $\left(0.7\right.$ and $\left.0.9^{\circ} \mathrm{C}\right)$.

Month temperature $\left({ }^{\circ} \mathrm{C}\right)$

\begin{tabular}{|l|c|c|c|c|c|c|c|}
\hline & Tw & Tmax & Tmin & Thm & Tim & Th & T1 \\
\hline Highest & 23.7 & 38.7 & 26.2 & 42.4 & 22.5 & 44.4 & 19.4 \\
\hline Lowest & 17.2 & 27.8 & 13.4 & 30.6 & 09.9 & 33.3 & 06.1 \\
\hline Range & 06.5 & 10.9 & 12.8 & 11.8 & 12.6 & 11.1 & 13.3 \\
\hline
\end{tabular}

Table

$\mathrm{Tw}=$ mean afternoon wet bulb, Tmax = mean maximum,

Tmin = mean minimum, Thm = highest mean, Tlm = lowest mean, $\mathrm{Th}=$ highest in a day, $\mathrm{Tl}=$ lowest in a day,

Agriculture was/is adapted to such variations in temperatures. However, in the last two decades groups are polluting agriculture research under the disguise of global warming, a component of climate change (Reddy, 2016). Moisture is the limiting factor in tropical warm countries where most of the developing countries are located. Moisture is expressed by rainfall/snowfall.

\section{Climate change}

The term "climate change" was defined by IPCC and UNFCCC. However, at local and regional levels they are affected by Climate Systems and General Circulation Patterns [6]. These are part of natural variability. Also, with the population growth and their action on nature are adding new twists to climate change. This is termed as human induced trend. Trend is a permanent feature. In rainfall, only natural variability is present. However, in temperature both trend and natural variability are present.

\section{Temperature}

The carbon dioxide levels in the Southern Hemisphere (SH) are far lower than those in the Northern Hemisphere (NH). It is also true with country to country. Same is the case with the temperature. That means it is not global phenomenon but it is a regional phenomenon and averaged. We must not forget the fact that wild animal dominated the world before industrial revolution. Domesticated animal replaced the wild animal population globally. Methane gas has short life while carbon dioxide $\left(\mathrm{CO}_{2}\right)$ has long life in the atmosphere. So, methane gas contribution to greenhouse gases is not an important component. Same is the case with other air pollutants that have very short life but have direct impact on life forms on the Land and in the Oceans $[7,8]$. The $\mathrm{CO}_{2}$ levels in the atmosphere are linearly related to population. By bringing down the population growth drastically, $\mathrm{CO}_{2}$ will also comedown drastically.

IPCC report showed $1.53^{\circ} \mathrm{C}$ changes for land. This cannot be called as global warming but it is only an average. Also, it is contaminated by urban-heat-island effect factor. -- And $0.87 \mathrm{oC}$ for land + ocean from 1850-1900 to 2006-2015. The second fallacy is, all those presented in $1^{\text {st }}$ para at global level has no meaning and on the contrary they should be calculated those parameters at local, regional, national and thus global level instead of harping on global warming a non-existed parameter. The temperature anomaly estimates have large limitations. For example:

- The network of met stations has been increased with the time and with the satellite era they have been gradually coming down on land surface. Though oceans occupy two-thirds of globe, the network is dismal low and accuracy is big question. Also, there is no balance between urban [densely distributed over smaller area] and rural [sparsely distributed over the large area] met network. This makes imbalance contribution to global anomaly by overemphasizing the urban heat island component and underemphasizing the rural cold island component; and thus as a result positive contributions to average.

- According IPCC, 1951 was the starting year of global warming; and in human impact component [trend] more than half is contributed by greenhouse effect and less than half by non-greenhouse effect. So, the changes in temperature presented above are not global warming. If we assume that in more than half, $50 \%$ is due to global warming, then they are: $0.765^{\circ} \mathrm{C}$ and $0.435 \mathrm{oC}$.

- $\quad$ Reddy [9] presented the natural variability and trend using the data series of 1880 to 2010 . The moving average suggested the natural variability follows the 60 year cycle, varies between -0.3 and $+0.3^{\circ} \mathrm{C}$ and the trend showed $0.6^{\circ} \mathrm{C} /$ Century. Thus the global warming is $0.6 \mathrm{x}$ $0.5=0.3^{\circ} \mathrm{C} /$ Century. Then from 1951 to 2100 it is $0.45^{\circ} \mathrm{C}$. This is for linear trend. IPCC presented climate sensitivity factor gradually coming down. That means it follows the non-linearly, gradually coming down in entire greenhouse effect as the energy emitted by the Sun is constant with natural variability associated with the Sunspot cycle; and net radiation from the ground followed the 
same (Reddy., et al. published this in 1977). Also, night temperatures are showing higher rise over the day temperatures, which is primarily associated with the urban heat-island effect. So, urban factor is contributing to higher rise in average land temperatures. This would have countered by the rural factor but this is missing.

- $\quad$ By taking all these factors in to account, we can safely say that practically there is no global warming - original satellite data supported this but this was removed from the internet (Reddy, 2008). However, urban heat island effect is going up and up with bulging of unplanned urban areas. Rise in temperature is not confined to ground level but also to higher layers of the atmosphere depending up on the vertical structure [distribution/density]. This is affecting power consumption [more $\mathrm{CO}_{2}$ -- not a pollution; we inhale air, use oxygen and release $\mathrm{CO}_{2}$ -- is released]. This is the major issue to be talked by governments on priority basis. Now Indian Government made Ladak as UT and this may lead to unplanned/reckless growth, which will severely change the climate and destruction of natural resources [water bodies/rainfall/snowfall], etc. Thus, what IPCC said in $1^{\text {st }}$ para may be possible in Ladak in near future due to human greed but not due to GHG.

- $\quad$ Heat and Cold waves are part of natural system. In India, they are associated with Western Disturbances, a general circulation pattern, in the northwest India. Reddy and Rao published in 1978 how the heat or cold waves move over different parts of India. Even today there is no change. Unfortunately UN agencies don't care to look in to such systems as their agenda of climate change is different. Under the general circulation pattern, low pressure system in West Bengal creates dry conditions in Hyderabad.

IPCC reported that Himalayan Glaciers will melt by 2035 and $\mathrm{Al}$ Gore reported that Greenland ice will melt in five years. On our questioning on the veracity of such conclusions, IPCC and Al Gore waited for Nobel Prize and withdrew their conclusions but did not return the Nobel Prize money. After returning from COP21 Paris summit on climate change in 2015 the environment minister informed to the Indian Parliament that $86.6 \%$ of Himalayan Glaciers are stable out of 2181.

If sea levels are rising, why Al Gore acquired Beach House? That means, really speaking there is no sea level rise associated with global warming; but in some areas these are associated with sinking of coastal zones due to extraction of water, oil and gas [southern parts of USA] and destruction of coastal protective walls [mangrove forests], etc. $[1,6]$.
[6] WMO Press note on extreme weather events on the occasion of WMO Day (23-3-2014) it was observed linking global warming to droughts in SH nations. I sent a reply saying they are part of natural variability in rainfall and has nothing to do with global warming [which is non-existing] and suggested to refer my book available in WMO Library for verification on facts.

\section{Rainfall}

In rainfall, there is no trend but there is shift associated with changes in localized or regionalised Climate System. WMO in 1966 brought out a manual on climate change. This manual presented methods to separate natural variability from human induced trend. It also presented methods to characterize the cyclic nature in rainfall data series. This manual was prepared by eminent meteorologists from met departments around the globe.

In Indian Parliament a question was asked on Delhi normal date of onset of monsoon. We were assigned to respond on this. In that connection, I collected the dates of onset and withdrawal for all met sub-divisions in India from DWR, WWR, and MWR - no data was available in electronic systems. I worked out a method for forecasting the onset of SWM [linking with Stratosphere winds over Singapore]. As part of it, time series of onset dates for Kerala were platted. The 10-year moving average showed a 52 year cyclic pattern; I published this in 1977. Same was also seen in Fortaleza rainfall in northeast Brazil in the Southern Hemisphere around the same latitude; I published this in 1984. I studied the rainfall of Mahalapye in Botswana in 1981; also studied the data series of Mozambique and Ethiopia \{published in 1986 and 1990). These are presented by Reddy $[3,4]$. They all showed systematic rhythmic variations. Recently there was a hue- and- cry on drought conditions in Cape Town in South Africa and wet conditions [Idai Cyclone] in Beira in Mozambique. I predicted them and published in 1986 - for Beira with the average rainfall of $1480 \mathrm{~mm}$ : the wet 2012 to 2038 with 2023-2027 dry periods; and for Durban with the average rainfall of $1050 \mathrm{~mm}$ : the dry 2010-2042 with 2024-2028 wet periods.

In 2000 in a book I presented the cyclic nature of Indian rainfall and Andhra Pradesh Rainfall. Now in all India annual rainfall started below the average 30 year part of the 60 -year cycle. These were linked to water availability in Godavari River, etc. [4,5,10]. Andhra Pradesh state annual rainfall presented 132 year cycle. One full 
cycle completed and the second cycle started in 2001 starting with below the average 66 year cycle part. In this part more drought years are possible - it is already experienced by the states. Krishna River water followed this pattern. However, SWM and NEM rainfall series showed 56 year cycle but in opposite direction [similar to Atlantic and Pacific Ocean temperature 60 year cycle]. The cyclonic activity in Bay of Bengal showed similar to SWM 56-year cycle. At local level in Kurnool, the analysis showed drought in 45\% of the years. This followed the SWM rainfall pattern of 56 years cycle and thus during below the average period the drought condition will be in $70 \%$ of the years and in the above the average period, it is only $30 \%$ of the years.

These play vital role to achieve sustainability - however scientists-institutions are misleading governments on rainfall and water availability issues -- in agriculture and food security issues $[8,10]$. However, both quantity and quality of foods are important both on land and in water/oceans. The quality is affected by pollution $[5,7,8,10]$. On request submitted my suggestions in this regard to "Food Security and Nutrition: Building a global narrative towards 2030", From 3 December 2018 to 28 January 2019, www.fao.org/ fsnforum/cfs-hlpe/discussions/global_FSN_narrative, on online. My suggestion is $13^{\text {th }}$ in the list [www.fao.org/fsmforum]. One of the ten points under this is [see at the end all points]:

How and why do diets change?

"One is associated with the food production through farming systems practices in agriculture and the other is non-agriculture system - animal meet and sea food. Under traditional agriculture farmers used to produce nutrient rich food including milk. With the chemical input agriculture technology this is drastically modified and now people get poor quality polluted diet including adulterated food. Even the sea/river/pond foods are contaminated with pollution. Cereals and pulses were important food components under traditional system. Now vegetables are consumed more but they are contaminated with polluted water use in producing them".

In 1985 presented and published the analysis results of rainfall data of India, Upper Volta [Burkina Faso], Senegal and North Western Australia -- included water balance simulations to North Western Australian stations [Pine Creek, Argyle Downs, Derby, Atherton, Mt Surprise, Woodstock, Clermont, Marlborough, Mitchell] and
Niger stations [Niamey Ville and Maradi]. This study brought out the fact why commercial agriculture failed in the North Western Australia. Also a bulletin was brought out in 1981 presenting the rainfall condition in West Africa [Senegal, Mali, Upper Volta, Niger and Tchad]. In all these there was no GHG impact.

\section{Bibliography}

1. Reddy SJ. "Role of Climate Change on Recent Weather Disasters”. Acta Scientific Agriculture 2.4 (2018a): 22-29.

2. Reddy SJ. Impact of "Climate Change and Human Interference" on Water Resources Availability in India. Presented at AICE'18 Total Water Solutions held at Hyderabad on 16-17th November 2018 by American Water Association [AWWA] (2018b).

3. Reddy SJ. "Agroclimatic/Agrometeorological Techniques: As applicable to Dry-land Agriculture in Developing Countries". Agricultural and Forest Meteorology 67 (1993): 325-327.

4. Reddy SJ. Agroclimatic/Agrometeorological Techniques: As applicable to Dry-land Agriculture in Developing Countries [2nd Edition]', “Brillion Publishing”, New Delhi (2019a): 372.

5. Reddy SJ. Workable Green Revolution: Agriculture in the perspective of Climate Change". Brillion Publishing, New Delhi (2019b): 221.

6. Reddy SJ. "Climate Change and its Impacts: Ground Realities". BS Publications, Hyderabad, India (2016): 276.

7. Reddy SJ. "Impacts of pollution on environment: Myths and Realities!!”. Compendium, Platinum Jubilee Celebrations of Andhra Pradesh State Centre (1938-2013), The Institute of Engineers (India) (2013): 9-16.

8. Reddy SJ. "Water-logging and water productivity in Agriculture". Proc. 4th International Conference on 'Hydrology and Watershed Management [ICHWAM-2014]. 2 (2014): 683-692.

9. Reddy SJ. “Climate Change: Myths and Realities”. (2008): 205.

10. Reddy SJ. "Water Resources Availability in India”. Brillion Publishing, New Delhi (2019c): 224.

\section{Volume 3 Issue 9 September 2019 (C) All rights are reserved by $S$ Jeevananda Reddy.}

